\title{
Antiproliferation potential of withaferin A on human osteosarcoma cells via the inhibition of G2/M checkpoint proteins
}

TING-ZHUO LV and GUANG-SHUN WANG

\author{
Department of Orthopedics, Baodi District People's Hospital of Tianjin City, Tianjin 301800, P.R. China
}

Received June 2, 2014; Accepted February 24, 2015

DOI: $10.3892 / \mathrm{etm} .2015 .2480$

\begin{abstract}
Withaferin A (WA) is a well-known steroidal lactone of the medicinally important plant, Withania somnifera. This secondary metabolite has been noted for its anticancer effects against a number of human cancer cell lines. However, there are a limited number of studies investigating the growth inhibitory potential of WA against human osteosarcoma cells and the underlying molecular mechanisms. Thus, in the present study, the antiproliferative activities of WA, along with the underlying mechanisms of action, were investigated using flow cytometry for cell cycle distribution and western blot analysis for the assessment of various checkpoint proteins. In addition, the antiproliferative activity was evaluated using a sulforhodamine B assay, where MG-63 and U2OS human osteosarcoma cell lines were treated with different concentrations of WA. Furthermore, the mRNA expression levels of the checkpoint proteins in the WA-treated MG-63 and U2OS cells were examined. The results obtained corresponded with the western blot analysis results. Furthermore, WA was shown to significantly inhibit the proliferation of the two types of treated cell lines (MG-63 and U2OS). Flow cytometric analysis revealed that WA induced cell cycle arrest at the G2/M phase, which was associated with the inhibition of cyclin B1, cyclin A, $\mathrm{Cdk} 2$ and $\mathrm{p}-\mathrm{Cdc} 2$ (Tyr15) expression and an increase in the levels of p-Chk1 (Ser345) and p-Chk2 (Thr68). In conclusion, the present study found that the antiproliferative potential of WA was associated with the induction of cell cycle arrest at the $\mathrm{G} 2 / \mathrm{M}$ phase, which was a result of the attenuation of the expression levels of $\mathrm{G} 2 / \mathrm{M}$ checkpoint proteins.
\end{abstract}

\section{Introduction}

Cancer is a major human disease that causes a considerable economic burden to health institutions worldwide. Although

Correspondence to: Mr. Ting-Zhuo Lv, Department of Orthopedics, Baodi District People's Hospital of Tianjin City, 8 Guangchuan Road, Tianjin 301800, P.R. China

E-mail: lvtingzhuo@gmail.com

Key words: apoptosis, withaferin A, withanolides, adenocarcinoma, phosphorylation significant progress has been made in cancer treatment, the incidence and mortality rates for almost every type of cancer remain high (1). Thus, further research is required to develop safe and effective drugs for the treatment of human cancers. Among the various types of cancer, primary malignant osteosarcoma predominantly affects the growing bones of adolescents and children, and is characterized by locally aggressive growth and an early metastatic potential (2). The incidence rate of osteosarcoma among younger individuals ( $<20$ years-old) is 8.7 per million, and this rate is higher in males compared with females (3). Respiratory failure due to lung metastasis is the major cause of mortality in patients, despite significant improvements in clinical treatments with combination intensive chemotherapy and surgical resection $(4,5)$. However, patients frequently suffer from intolerable, acute and long-term toxicities following the administration of approved chemotherapeutic agents (6). Thus, more effective and improved treatment strategies are required to prevent the progression of osteosarcoma.

Withanolides (steroidal lactones) have been isolated from various species of the Solanaceae family, including Withania somnifera (W. somnifera), which is widely distributed across the South Asian subcontinent (7). In the Ayurveda system of medicine, Withania is noted for its aphrodisiac, sedative and life-prolonging properties (8). Extracts from different parts of $W$. somnifera have been evaluated for various biological activities, such as cholinesterase inhibition $(9,10)$, anti-inflammatory properties via cyclooxygenase-2 enzyme inhibition from leaf extracts (11), antibacterial properties (12) and sex hormone deficiency regulation in rats with diabetes (13). The isolation and identification of several withanolides with anti-glycation (14) and antipyretic activities (15) from Withania has been reported. Among the reported withanolides, withaferin A (WA) (16) (as seen in Fig. 1) and ashwagandhanolide (17), obtained from the leaves and roots, respectively, are well-known potent secondary metabolites of W. somnifera and are reported to possess anticancer properties. Antiproliferative, antimetastatic, antiangiogenic, anti-invasive and proapoptotic activities of withanolides have been reported, with the underlying mechanism found to be associated with the suppression of nuclear factor (NF) $\mathrm{\kappa B}$ and NF- $\mathrm{KB}$-regulated gene products (18). Previous studies have demonstrated the anticancer activity of WA in prostate $(19,20)$, breast $(21)$, leukemia (22) and melanoma cancer cells (23). In addition, a previous study demonstrated that WA induces apoptosis in 
prostate cancer cells through Par-4 induction (19) and inhibits I $\kappa$ B kinase activation via a thioalkylation-sensitive redox mechanism (24); by covalently modifying the cysteine residue, WA targets the intermediate filament protein, vimentin (25). Furthermore, WA has been shown to induce actin microfilament aggregation by targeting annexin II (26). The aim of the present study was to investigate the antiproliferative effects of WA on two osteosarcoma cell lines (U2OS and MG-63) and determine the mechanism underlying the induction of cell cycle arrest.

\section{Materials and methods}

Reagents. WA, bovine serum albumin (BSA), ribonuclease A (RNase A), propidium iodide (PI), sulforhodamine B (SRB) and a rabbit polyclonal anti- $\beta$-actin antibody $(1: 1,000$; cat. no. A2668) were purchased from Sigma-Aldrich (St. Louis, MO, USA). Fetal bovine serum (FBS), RPMI 1640 medium, trypsin-EDTA and antibiotic-antimycotic were purchased from Gibco Life Technologies (Grand Island, NY, USA). The following antibodies: Rabbit polyclonal Cdk2 (1:1,000; cat. no. sc-163), rabbit polyclonal cyclin A $(1: 1,000$; sc-751), mouse monoclonal cyclin B1 (1:1,000; cat. no. sc-245) and mouse monoclonal Cdc2 (1:1,000; cat. no. sc-54) were purchased from Santa Cruz Biotechnology, Inc. (Santa Cruz, CA, USA). The following antibodies: Rabbit polyclonal p-Cdc2 (Tyr15; 1:1,000; cat. no. P06493), rabbit polyclonal p-Chk1 (Ser345; 1:1,000; cat. no. 2341S), rabbit polyclonal p-Chk2 (Thr68; 1:1,000; cat. no. 2661), rabbit polyclonal Chk1 (1:1,000; cat. no. 2344S) and rabbit polyclonal Chk2 (1:1,000; cat. no. 2662) were obtained from Cell Signaling Technology, Inc. (Danvers, MA, USA).

Ethics and cell lines. U2OS and MG-63 human osteosarcoma cell lines were obtained from the China Center for Type Culture Collection (Wuhan, China), following standard ethical procedures (27). Following isolation, the osteosarcoma cells were identified based on histological type and grade. The cell lines were grown in high glucose Dulbecco's modified Eagle's medium supplemented with $10 \% \mathrm{FBS}, 100 \mathrm{U} / \mathrm{ml}$ penicillin $\mathrm{G}$ and $100 \mathrm{U} / \mathrm{ml}$ streptomycin (Sigma-Aldrich). The cells were subsequently incubated in a humidified incubator at $37^{\circ} \mathrm{C}$ with $5 \% \mathrm{CO}_{2}$. All cells used in the experiments were in the logarithmic phase.

Cell proliferation assay. The antiproliferation potential of WA in U2OS and MG-63 cells was examined using an SRB assay (11). Cell lines were seeded at a density of $9 \times 10^{3}$ cells/well into 96-well plates and allowed to adhere for $72 \mathrm{~h}$. The cells were subsequently treated with WA at various concentrations (0.1, 1 and $10 \mu \mathrm{M})$. Dimethyl sulfoxide (DMSO) was used as the experimental control. The results were presented as percentages relative to the solvent-treated control incubations. Using nonlinear regression analysis, the $\mathrm{IC}_{50}$ values were calculated.

Cell cycle analysis. U2OS and MG-63 cell lines were plated into $35-\mathrm{mm}$ culture dishes at a density of $1 \times 10^{6}$ cells $/ 100 \mathrm{~mm}$ and incubated for $24 \mathrm{~h}$. The medium was replaced with fresh medium containing WA (at concentrations of $0.1,1$ and $10 \mu \mathrm{M}$ ) and $0.1 \%$ DMSO alone. Following incubation for $24 \mathrm{~h}$ at $37^{\circ} \mathrm{C}$, the cells were harvested, washed with phosphate-buffered saline and fixed with $70 \%(\mathrm{v} / \mathrm{v})$ ice-cold ethanol for $1 \mathrm{~h}$ at $4^{\circ} \mathrm{C}$. Subsequently, $50 \mu \mathrm{g} / \mathrm{ml}$ RNase A and $50 \mu \mathrm{g} / \mathrm{ml}$ PI were added to the fixed cells. In total, 10,000 cells were analyzed by flow cytometry (BD Accuri ${ }^{\mathrm{TM}}$ C6; BD Biosciences, Franklin Lakes, NJ, USA). All experiments were repeated three times and data analysis was recorded using BD CellQuest ${ }^{\mathrm{TM}}$ cell cycle analysis software (BD Biosciences).

Western blot analysis. U2OS and MG-63 cell lines were incybated with varying concentrations of WA $(0.1,1$ and $10 \mu \mathrm{M}$ ) for $24 \mathrm{~h}$. The cell samples were lysed in sample buffer [150 mM Tris (pH 6.8), $8 \mathrm{M}$ urea, $50 \mathrm{mM}$ DTT, $2 \%$ sodium dodecyl sulfate, $15 \%$ sucrose, $2 \mathrm{mM}$ EDTA, $0.01 \%$ bromophenol blue and $1 \%$ protease and phosphatase inhibitor cocktails], sonicated (Ultrasonic Homogenizer 300MP; BioLogics, Manassas, VA, USA) and the protein concentrations were recorded using the Lowry protein assay method (28). Subsequently, samples of 40-45 $\mu \mathrm{g}$ were refluxed, run through an 8-12\% Bis/Tris gel (Invitrogen Life Technologies, Carlsbad, CA, USA) using 5X 2-(N-morpholino)ethanesulfonic buffer (Sigma-Aldrich) and transferred to an Immobilon-nitrocellulose membrane (Sigma-Aldrich). The membrane was blocked with 5\% skimmed milk or 3\% BSA in Tris-buffered saline Tween-20 [TBST; $150 \mathrm{mM} \mathrm{NaCl}, 50 \mathrm{mM}$ Tris $(\mathrm{pH} \mathrm{7.5)}$ and $0.1 \%$ Tween-20] (blocking buffer). Next, the membrane was probed with antibodies targeted against cyclin A, cyclin B1, Cdk2, p-Cdc2 (Tyr15), Cdc2, p-Chk1 (Ser345), Chk1, p-Chk2 (Thr68), Chk2 and $\beta$-actin $(1: 1,000)$ overnight at $4^{\circ} \mathrm{C}$ in blocking buffer. Following washing with TBST, the membranes were probed with anti-rabbit (cat. no. 7074; Cell Signalling Technology, Inc.) and goat anti-mouse (cat. no. 11011MP; Life Technologies, Grand Island, NY, USA) immunoglobulin G secondary antibodies $(1: 5,000)$ in blocking buffer at room temperature for $90 \mathrm{~min}$, and after washing again, the fluorescence was subsequently detected using a Bio-Rad imaging system (Bio-Rad Laboratories, Hercules CA, USA).

Reverse transcription quantitative polymerase chain reaction (RT-qPCR) assay. In the RT-qPCR analysis, the two cell lines were treated with $10 \mu \mathrm{M}$ WA for $12 \mathrm{~h}$. Extraction of the total cellular RNA was performed using TRIzol ${ }^{\circledR}$ reagent (Invitrogen Life Technologies), according to the manufacturer's instructions. For reverse transcription of the RNA into cDNA, a SuperScript III First-Strand Synthesis kit (Invitrogen Life Technologies) was used. Subsequently, the qPCR was conducted using an ABI Prism 7900HT Real-Time PCR system (PerkinElmer, Inc., Waltham, MA, USA) with SYBR Green PCR Master Mix (Applied Biosystems Life Technologies, Foster City, CA, USA). The primers used in the RT-qPCR analysis are presented in Table I. The mRNA expression levels were recorded as the fold change relative to the control. Following completion of the RT-qPCR, cycle numbers (Ct values) in which the signal intensity was equal to the threshold value were obtained from the software (SDS Plate Utility v2.3; Applied Biosystems Life Technologies). The relative expression values were calculated using the $2^{-\Delta \Delta \mathrm{Ct}}$ method (29). 
Table I. Primer sequences used for reverse transcription quantitative polymerase chain reaction.

\begin{tabular}{lll}
\hline Gene & \multicolumn{1}{c}{ Forward primer (5'-3') } & \multicolumn{1}{c}{ Reverse primer $\left(5^{\prime}-3^{\prime}\right)$} \\
\hline Cdk2 & GAAACTCTGAAGCCGACCAG & GCCCTCTCAGTGTCCAGAAG \\
Cyclin B1 & CGGGAAGTCACTGGAAACAT & AAACATGGCAGTGACACCAA \\
Cyclin A1 & GTCAGAGAGGGGATGGCAT & CCAGTCCACCAGAATCGTG \\
Cdc2 & GGTTCCTAGTACTGCAATTCG & TTTGCCAGAAATTCGTTTGG \\
Chk1 & GGTGCCTATGGAGAAGTTCAA 2 & TCTACGGCACGCTTCATATC \\
$\beta$-actin & GGATGTTGAGGCTCACGA & TATGCCCTGGGACTGTGAGG \\
\end{tabular}

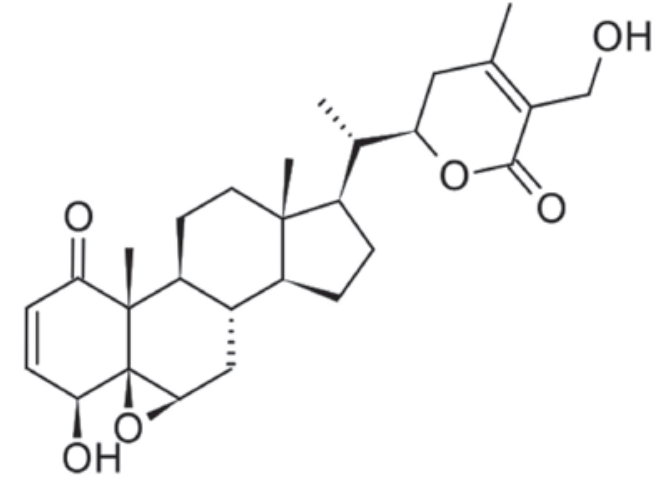

Figure 1. Chemical structure of withaferin A (molecular formula, $\mathrm{C}_{28} \mathrm{H}_{38} \mathrm{O}_{6}$; molecular mass, $470.60 \mathrm{~g} / \mathrm{mol})$.

Statistical analysis. All experiments were repeated a minimum of three times. Data are expressed as the mean \pm standard deviation. The treated groups were compared using one-way analysis of variance with SPSS 12.0 software (SPSS, Inc., Chicago, IL, USA), where $\mathrm{P}<0.05$ was considered to indicate a statistically significant difference. Relative percentages were calculated using GraphPad Prism software, version 4.0 for Windows (GraphPad Software, Inc., San Diego, CA, USA).

\section{Results}

WA prevents the proliferation of $M G-63$ and U2OS osteosarcoma cells. Two human osteosarcoma cells lines, MG-63 (Fig. 2A) and U2OS (Fig. 2B), were treated with varying concentrations of WA for $72 \mathrm{~h}$ to assess the antiproliferative effect of WA. The cell proliferation of each of the tested samples was recorded using an SRB assay. Higher concentrations of WA were shown to exhibit potent antiproliferative effects. Thus, the results revealed that WA produced a potent antiproliferative effect by significantly inhibiting the growth of the tested cell lines.

Effect of WA on cell cycle distribution. MG-63 and U2OS cells were treated with varying concentrations of WA for $24 \mathrm{~h}$ and the underlying antiproliferative mechanisms were investigated via flow cytometric analysis with PI staining. Cell cycle distribution analysis revealed that WA administration resulted in the significant arrest of MG-63 and U2OS human osteosarcoma cells at the $\mathrm{G} 2 / \mathrm{M}$ phase in a dose-dependent
$\mathbf{A}$

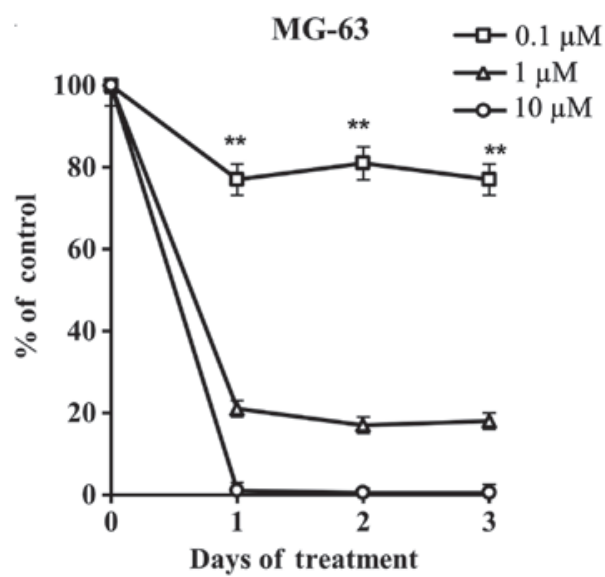

B

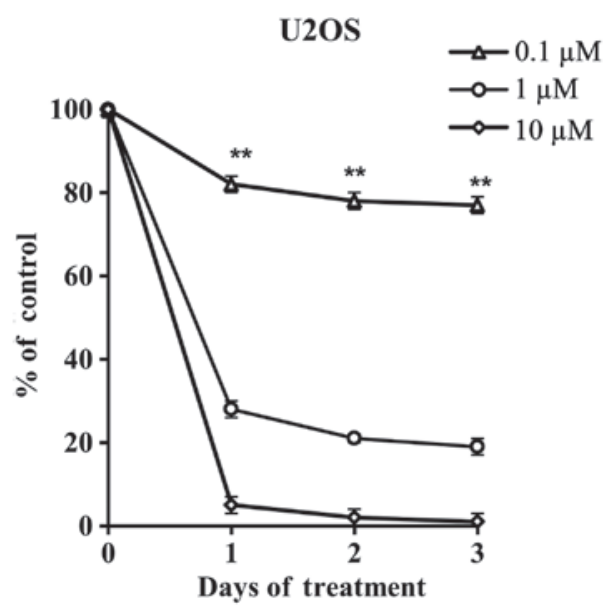

Figure 2. Effect of withaferin A on the proliferation of MG-63 and U2OS osteosarcoma cells. MG-63 and U2OS cells were plated on 96-well plates in RPMI medium supplemented with $10 \%$ fetal bovine serum, and incubated with different concentrations of the test compound for $72 \mathrm{~h}$. The antiproliferative effect was determined using a sulforhodamine B assay. The total percentage of cell growth was calculated as the mean absorbance of samples/absorbance of the vehicle-treated control. Data are presented as the mean \pm standard deviation $(n=3) .{ }^{* *} \mathrm{P}<0.01$, as compared with the control.

manner (Fig. 3). At a concentration of $10 \mu \mathrm{M}$ WA, more than half of the cells were arrested at the G2/M phase.

Western blot analysis on the expression levels of G2/M phase cell cycle checkpoint proteins. Western blot analysis was used to examine the expression levels of $\mathrm{G} 2 / \mathrm{M}$ cell cycle regula- 

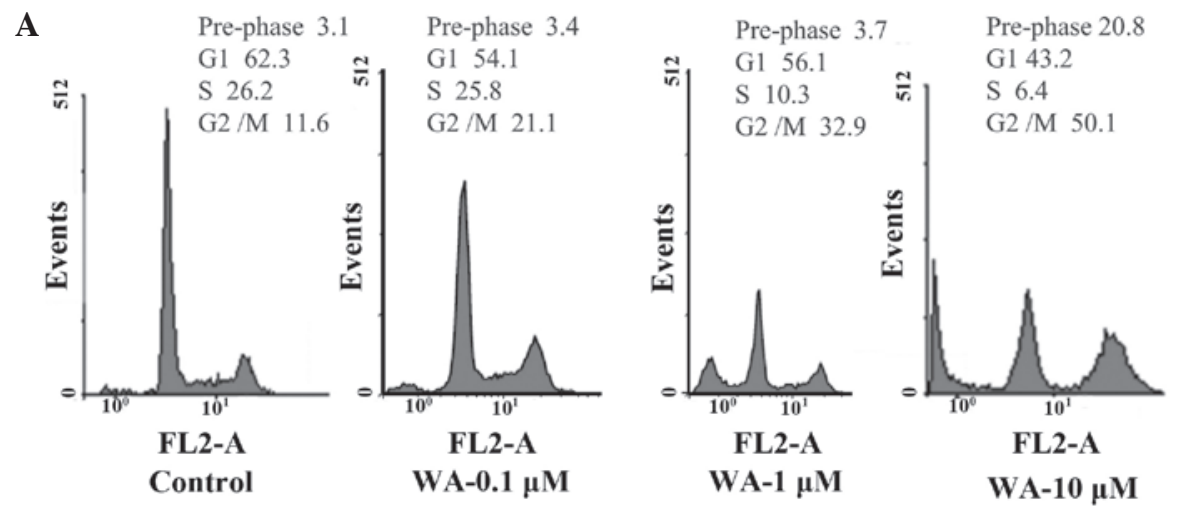

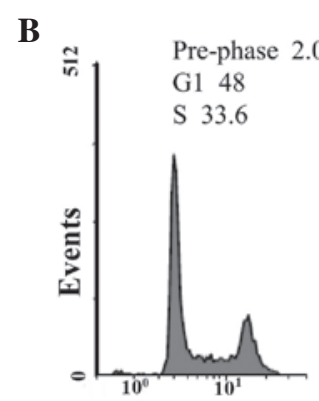

FL2-A

Control

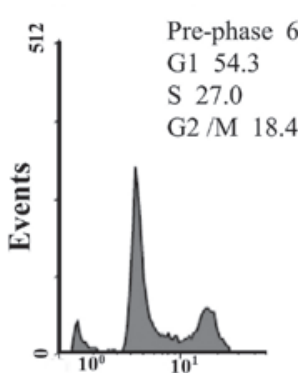

FL2-A

WA- $0.1 \mu \mathrm{M}$

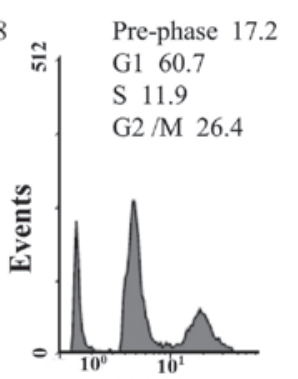

FL2-A

WA-1 $\mu \mathrm{M}$

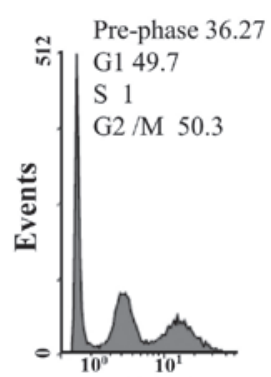

FL2-A

WA-10 $\mu \mathrm{M}$

Figure 3. Effect of WA on the regulation of cell cycle distribution in MG-63 and U2OS cells. Cells were seeded at a density of $1 \times 10^{6}$ cells $/ 100 \mathrm{~mm}$ dish in RPMI medium supplemented with $10 \%$ fetal bovine serum, and treated with various concentrations of WA for $24 \mathrm{~h}$. The cell cycle distribution was analyzed by flow cytometry. WA, withaferin A.

A

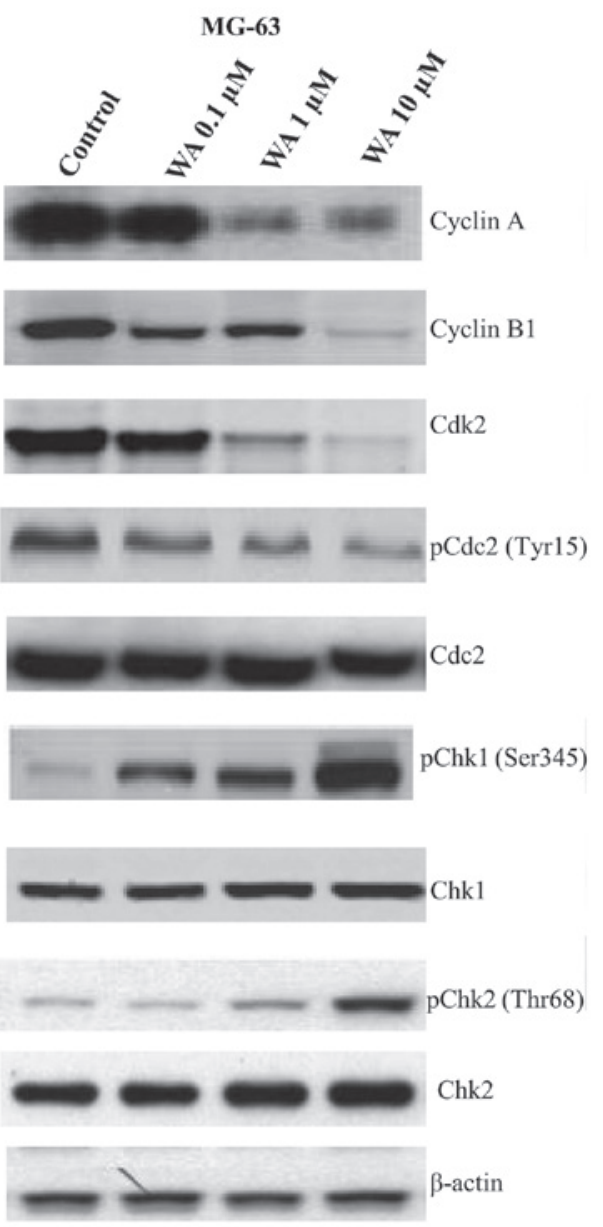

B
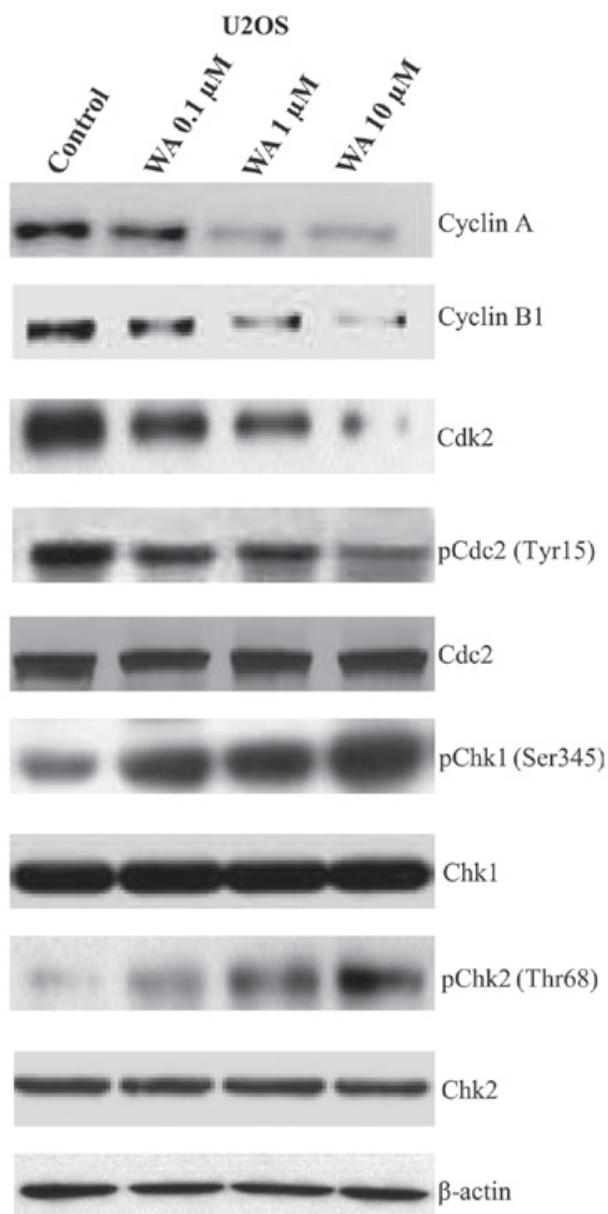

Figure 4. Effect of WA on the expression levels of cell cycle-associated proteins in MG-63 and U2OS cells. Cells were treated with the indicated concentrations of WA for $24 \mathrm{~h}$. The expression levels of the proteins were analyzed by western blot analysis. WA, withaferin A. 
A

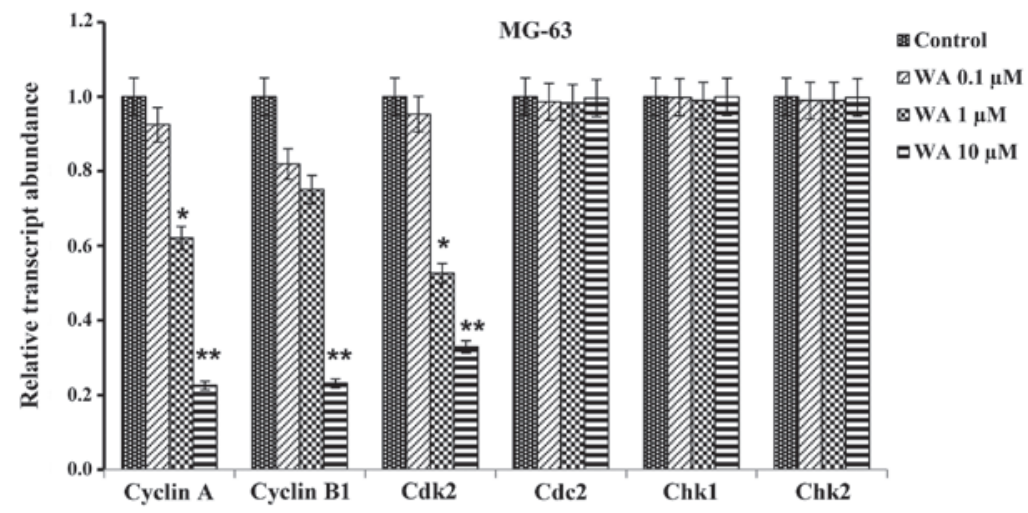

B

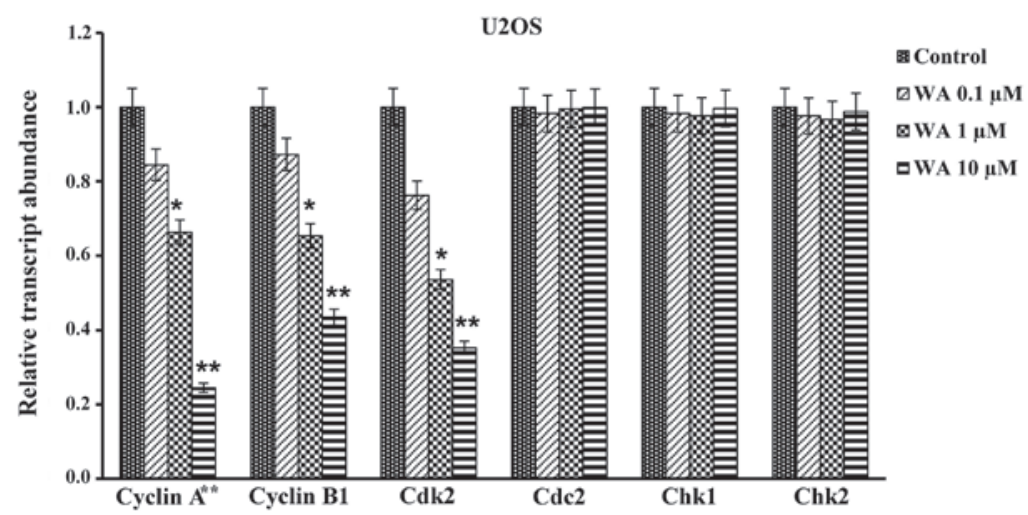

Figure 5. Effect of WA on the mRNA expression levels of cell cycle-associated proteins. MG-63 and U2OS cells were treated for $24 \mathrm{~h}$ with various concentrations of WA, and the mRNA expression levels were measured by reverse transcription quantitative polymerase chain reaction. The results obtained were in agreement with the western blot analysis results, with a maximum decrease in mRNA expression levels observed with $10 \mu \mathrm{M}$ WA treatment in the two cell lines. WA, withaferin $\mathrm{A} .{ }^{*} \mathrm{P}<0.05$ and ${ }^{* *} \mathrm{P}<0.01$, as compared with the control.

tory proteins in MG-63 (Fig. 4A) and U2OS (Fig. 4B) human osteosarcoma cell lines treated with WA, in order to determine whether the cell cycle arrest was associated with the regulation of cell cycle checkpoint proteins. There was a significant decrease in the levels of cyclin A, cyclin B1, Cdk2 and p-Cdc2 (Tyr15) in the MG-63 and U2OS cells; however, the protein expression levels of p-Chk1 (Ser345) and p-Chk2 (Thr68) increased. No statistically significant changes were observed in the levels of Cdc2 and Chk2 in the two cell lines following WA treatment.

Effect of WA on the mRNA expression levels of the cell cycle checkpoint proteins. In order to determine the effect of WA on the mRNA expression levels of cell cycle checkpoint proteins, the expression levels of $\mathrm{G} 2 / \mathrm{M}$ cell cycle regulatory proteins, including cyclin A, cyclin B1, Cdk2, Cdc2, Chk1 and Chk2, were elucidated by RT-qPCR analysis for the MG-63 (Fig. 5A) and U2OS (Fig. 5B) cell lines. There was a significant decrease in the mRNA expression levels of cyclin A, cyclin B1 and Cdk2, while no marked changes were observed in the mRNA expression levels of Cdc2, Chk1 and Chk2 in the two cell lines.

\section{Discussion}

WA is a well-known steroidal lactone from the withanolides group. These are major constituents identified from the impor- tant medicinal plant, Withania somnifera, and the related Solanaceae family (30). A number of biological properties of withanolides have been reported, including anti-inflammatory, antitumor, antibacterial, antidepressant, antioxidant, antiulcer, cytotoxic, quinone reductase inducive, antileishmanial, antitrypanosomal, immunosuppressive, cognition-enhancing and memory-improving effects, as well as hypotensive, bradycardic and respiratory-stimulating properties (31-33). Withanolides have been studied extensively, and $>130$ withanolides are known and $>40$ withanolides have been isolated (34). Certain newly-isolated withanolides, including withangulatins B, C, $\mathrm{G}, \mathrm{H}$ and I (33), have been shown to exert cytotoxic activity. Withanolide A possesses a reactive enone moiety in the A ring, an epoxy alcohol in the B ring, as well as a tetrasubstituted unsaturated lactone side chain. The main synthetic challenges arise from the stereoselective construction of the side chain, the oxidation pattern of the A and B ring, and the diastereoselective instalment of a tertiary alcohol at C20 (35). Furthermore, structure-activity relationship studies have confirmed that the unsaturated ring A and epoxide play an important role in the cytotoxic activity of withanolides (32). Withangulatin A has been shown to inhibit topoisomerase II and induce a heat shock response $(36,37)$. Zaarur et al (38) suggested that withangulatin A may induce the heat shock response by inhibiting Hsp90 activity.

The present study investigated the anticancer potential of WA in MG-63 and U2OS human osteosarcoma cancer cell 
lines. The results revealed that WA exhibited potent antiproliferative effects. Data from the cell cycle distribution analysis showed that WA treatment at a concentration of $10 \mu \mathrm{M}$ caused a significant accumulation of treated cells that were arrested in the G2/M phase; this effect was shown to be dose-dependent. Furthermore, western blot analysis revealed that WA significantly regulated the protein expression levels of G2/M cell cycle regulatory proteins in the two cell lines.

The key component involved in G2 to $\mathrm{M}$ phase transition is cyclin B1 (39). In addition, cyclin A/Cdk2 complexes are known to participate in the initiation of mitosis in human cancer cells (40). The DNA damage sensors, Chk1 and Chk2, participatein $\mathrm{G} 2 / \mathrm{Mcheckpoint}$ control throughtheataxia-telangiectasia mutated (ATM)/ATM-RAD3-related (ATR) pathway. In the current study, a significant decrease in the expression levels of cyclin A, cyclin B1, Cdk2 and p-Cdc2 (Tyr15) were observed, whereas the expression levels of p-Chk1 (Ser345) and p-Chk2 (Thr68) increased significantly in the two treated cell lines. At a concentration of $10 \mu \mathrm{M}$, WA was found to exhibit the maximal effect on protein expression and cell cycle arrest. At a transcription level, decreases in the mRNA expression levels of cyclin A, cyclin B1 and Cdk2 were observed, while no change was observed in the mRNA expression levels of Cdc2, Chk1 and Chk2 in the two treated cell lines.

In conclusion, the results of the present study demonstrated that the antiproliferative effects of WA on the human osteosarcoma cell lines, MG-63 and U2OS, at the G2/M phase were primarily associated with cell cycle arrest. These observations indicate that WA may be used in human osteosarcoma therapy following further clinical investigation. The main limitation of the present study was the recruitment of all participants from a single centre. This study may serve as a basis for future prospective studies. Future clinical investigation should be conducted prospectively, and include a large number of patients from various centres, so that results can be generalized.

\section{References}

1. Ferlay J, Soerjomataram I, Dikshit R, et al: Cancer incidence and mortality worldwide: Sources, methods and major patterns in GLOBOCAN 2012. Int J Cancer 136: E359-E386, 2015.

2. Arndt CA and Crist WM: Common musculoskeletal tumors of childhood and adolescence. N Engl J Med 341: 342-352, 1999.

3. Rodriguez-Galindo C, Baez F and Alcasabas AP: Bone Tumors. In: Pediatric Hematology-Oncology in Countries with Limited Resources. Stefan DC and Rodriguez-Galindo C (eds). Springer, New York, pp323-335, 2014.

4. Petrilli AS, de Camargo B, Filho VO, et al; Brazilian Osteosarcoma Treatment Group Studies III and IV: Results of the Brazilian Osteosarcoma Treatment Group Studies III and IV: prognostic factors and impact on survival. J Clin Oncol 24: 1161-1168, 2006.

5. Bielack SS, Kempf-Bielack B, Delling G, et al: Prognostic factors in high-grade osteosarcoma of the extremities or trunk: an analysis of 1,702 patients treated on neoadjuvant cooperative osteosarcoma study group protocols. J Clin Oncol 20: 776-790, 2002.

6. Chen Y,Han XZ, Wang W, Zhao RT and Li X: Withaferin A inhibits osteosarcoma cells through inactivation of Notch-1 signalling. Bangladesh J Pharmacol 9: 364-370, 2014.

7. Said HM (ed): Hamdard Pharmacopoeia of Eastern Medicine. 1st edition. Hamdard Academy, Karachi, Pakistan, 1970.

8. Williamson EM (ed): Major herbs of Ayurveda. Churchill Livingstone, Philadelphia, PA, USA, 2002.

9. Choudhary MI, YousufS,Nawaz SA, Ahmed S and Atta-ur-Rahman: Cholinesterase inhibiting withanolides from Withania somnifera. Chem Pharm Bull (Tokyo) 52: 1358-1361, 2004.
10. Choudhary MI, Nawaz SA, ul-Haq Z, Lodhi MA, et al: Withanolides, a new class of natural cholinesterase inhibitors with calcium antagonistic properties. Biochem Biophys Res Commun 334: 276-287, 2005.

11. Jayaprakasam B and Nair MG: Cyclooxygenase-2 enzyme inhibitory withanolides from Withania somnifera leaves. Tetrahedron 59: 841-849, 2003.

12. Owais M, Sharad KS, Shehbaz A and Saleemuddin M: Antibacterial efficacy of Withania somnifera (ashwagandha) an indigenous medicinal plant against experimental murine salmonellosis. Phytomedicine 12: 229-235, 2005.

13. KiasalariZ,Khalili Mand AghaeiM:Effect of Withania somnifera on levels of sex hormones in the diabetic male rats. Iran J Reprod Med 7: 163-168, 2009.

14. Maurya R, Akanksha, Jayendra, Singh AB and Srivastava AK: Coagulanolide, a withanolide from Withania coagulans fruits and antihyperglycemic activity. Bioorg Med Chem Lett 18: 6534-6537, 2008.

15. Ali M, Shuaib M and Ansari SH: Withanolides from the stem bark of Withania somnifera. Phytochemistry 44: 1163-1168, 1997.

16. Jayaprakasam B, Zhang Y, Seeram NP and Nair MG: Growth inhibition of human tumor cell lines by withanolides from Withania somnifera leaves. Life Sci 74: 125-132, 2003.

17. Subbaraju GV, Vanisree M, Rao CV, et al: Ashwagandhanolide, a bioactive dimeric thiowithanolide isolated from the roots of Withania somnifera. J Nat Prod 69: 1790-1792, 2006.

18. Ichikawa H, Takada Y, Shishodia S, Jayaprakasam B, Nair MG and Aggarwal BB: Withanolides potentiate apoptosis, inhibit invasion and abolish osteoclastogenesis through suppression of nuclear factor-kappaB (NF-kappaB) activation and NF-kappaB-regulated gene expression. Mol Cancer Ther 5: 1434-1445, 2006.

19. Srinivasan S, Ranga RS, Burikhanov R, Han S and Chendil D Par-4-dependent apoptosis by the dietary compound withaferin A in prostate cancer cells. Cancer Res 67: 246-253, 2007.

20. Yang H, Shi G and Dou QP: The tumor proteasome is a primary target for the natural anticancer compound Withaferin A isolated from 'Indian winter cherry'. Mol Pharmacol 71: 426-437, 2007.

21. Stan SD, Hahm E-R, Warin R and Singh SV: Withaferin A causes FOXO3a- and Bim-dependent apoptosis and inhibits growth of human breast cancer cells in vivo. Cancer Res 68: 7661-7669, 2008.

22. Malik F, Kumar A, Bhushan S, et al: Reactive oxygen species generation and mitochondrial dysfunction in the apoptotic cell death of human myeloid leukemia HL-60 cells by a dietary compound withaferin A with concomitant protection by $\mathrm{N}$-acetyl cysteine. Apoptosis 12: 2115-2133, 2007.

23. Devi PU, Kamath R and Rao BS: Radiosensitization of a mouse melanoma by withaferin A: in vivo studies. Indian J Exp Biol 38: 432-437, 2000.

24. Kaileh M, Vandin Berghe W, Heyerick A, et al: Withaferin A strongly elicits IkappaB kinase $\beta$ hyperphosphorylation concomitant with potent inhibition of its kinase activity. J Biol Chem 282: 4253-4264, 2007.

25. Bargagna-Mohan P, Hamza A, Kim YE, et al: The tumor inhibitor and antiangiogenic agent withaferin A targets the intermediate filament protein vimentin. Chem Biol 14: 623-634, 2007.

26. Falsey RR, Marron MT, Gunaherath GM, et al: Actin microfilament aggregation induced by withaferin $\mathrm{A}$ is mediated by annexin II. Nat Chem Biol 2: 33-38, 2006.

27. Emanuel EJ, Wendler D, Killen J and Grady C: What makes clinical research in developing countries ethical? The benchmarks of ethical research. J Infect Dis 189: 930-937, 2004.

28. Lowry OH, Rosebrough NJ, Farr AL and Randall RJ: Protein measurement with the Folin phenol reagent. J Biol Chem 193: 265-275, 1951.

29. Livak KJ and Schmittgen TD: Analysis of relative gene expression data using real-time quantitative PCR and the 2(-Delta Delta C(T)) method. Methods 25: 402-408,2001.

30. Kuroyanagi M, Shibata K and Umehara K: Cell differentiation inducing steroids from Withania somnifera L. (Dun). Chem Pharm Bull (Tokyo) 47: 1646-1649, 1999.

31. Mirjalili MH, Moyano E, Bonfill M, Cusido RM and Palazón J: Steroidal lactones from Withania somnifera, an ancient plant for novel medicine. Molecules 14: 2373-2393, 2009.

32. Damu AG, Kuo PC, Su CR, et al: Isolation, structures and structure - cytotoxic activity relationships of withanolides and physalins from Physalis angulata. J Nat Prod 70: 1146-1152, 2007.

33. Lee SW, Pan MH, Chen CM and Chen ZT: Withangulatin I, a new cytotoxic withanolide from Physalis angulata. Chem Pharm Bull (Tokyo) 56: 234-236, 2008. 
34. Tursunova R, Maslennikova V and Abubakirov N: Withanolides in the vegetable kingdom. Chem Nat Compd 13: 131-138, 1977.

35. Liffert R, Hoecker J, Jana CK, et al: Withanolide A: Synthesis and structural requirements for neurite outgrowth. Chem Sci 4: $2851-2857,2013$

36. Juang J-K, Huang HW, Chen CM and Liu HJ: A new compound, withangulatin A, promotes type II DNA topoisomerase-mediated DNA damage. Biochem Biophys Res Commun 159: 1128-1134, 1989.

37. Lee WC, Lin KY, Chen CM, Chen ZT, Liu HJ and Lai YK Induction of heat-shock response and alterations of protein phosphorylation by a novel topoisomerase II inhibitor, withangulatin A, in 9 L rat brain tumor cells. J Cell Physiol 149: 66-76, 1991.
38. Zaarur N, Gabai VL, Porco JA Jr, Calderwood S and Sherman MY: Targeting heat shock response to sensitize cancer cells to proteasome and Hsp90 inhibitors. Cancer Res 66: 1783-1791, 2006.

39. Jackman M, Lindon C, Nigg EA and Pines J: Active cyclin B1-Cdk1 first appears on centrosomes in prophase. Nat Cell Biol 5: 143-148, 2003.

40. Mitra J and Enders GH: Cyclin A/Cdk2 complexes regulate activation of Cdk1 and Cdc25 phosphatases in human cells. Oncogene 23: 3361-3367, 2004. 